\title{
Histiocytic sarcoma progressing from follicular lymphoma and mimicking acquired hemophagocytic lymphohistiocytosis
}

\author{
Christoph Schünemann ${ }^{1} \cdot$ Gudrun Göhring ${ }^{2} \cdot$ Yvonne Lisa Behrens ${ }^{2} \cdot$ Hans-Heinrich Kreipe ${ }^{3} \cdot$ Arnold Ganser $^{1}$. \\ Felicitas Thol ${ }^{1}$
}

Received: 13 July 2020 / Accepted: 15 July 2020 / Published online: 17 August 2020

(C) The Author(s) 2020

Dear Editor,

Histiocytic sarcoma (HS) is a rare and aggressive nonLangerhans cell histiocytosis with a poor prognosis [1]. In a subset of cases, HS is clonally related to concurrent hematological malignancies, especially lymphomas [2]. Acquired hemophagocytic lymphohistiocytosis (HLH) is a systemic reactive process that includes macrophage activation with hemophagocytosis in the bone marrow [3].

A 57-year-old woman presented with a progressive hypopharyngeal tumor. B symptoms were absent, and laboratory results were unremarkable. Histologic examination showed a blastic infiltration with monocytoid/histiocytic morphology with CD68, CD163, CD14, and lysozyme expression (CD1a, CD3, CD20, CD34, CD56, CD117, MPO and S100 negative, immunohistochemistry (IHC)) (Fig. 1a). Staging revealed mediastinal, mesenterial, and retroperitoneal lymphadenopathy as well as an incidental follicular lymphoma (FL) grade 1 in the bone marrow with otherwise unaffected hematopoiesis. Histiocyte infiltration of the bone marrow was excluded. Fluorescence in situ hybridization (FISH) revealed the presence of translocation $\mathrm{t}(14 ; 18)$ within the cervical HS as well as the FL of the bone marrow (Fig. 1b). Immunoglobulin heavy chain (IgH) rearrangement was present in the FL but absent in the cervical HS (PCR amplification). We diagnosed HS probably arising from follicular lymphoma.

Felicitas Thol

Thol.Felicitas@mh-hannover.de

1 Department of Hematology, Hemostasis, Oncology, and Stem Cell Transplantation, Hannover Medical School, Carl-Neuberg-Str.1, 30625 Hannover, Germany

2 Department of Human Genetics, Hannover Medical School, Carl-Neuberg-Str.1, 30625 Hannover, Germany

3 Institute of Pathology, Hannover Medical School, Carl-Neuberg-Str.1, 30625 Hannover, Germany
We initiated a therapy with R-CHOEP (rituximab, cyclophosphamide, doxorubicin, vincristine, prednisone with etoposide) and documented a stable disease after two cycles of therapy.

Subsequently, therapy continuation was delayed due to persisting fever. Extensive diagnostics and empiric antimicrobial therapies failed. The patient's general condition markedly worsened with onset of a sepsis-like syndrome with a high fever, tachycardia, and hypotension as well as an unexplained progressive pancytopenia. Another bone marrow aspirate showed slightly increased cellularity, normal hematopoiesis, and extensive hemophagocytosis (Fig. 1c).

Because of the clinical presentation and positive diagnostic criteria for HLH according to the HLH-2004 protocol [4] (5 out of 8 criteria, including rising ferritin of $7370 \mu \mathrm{g} / \mathrm{L}$ ), we suspected malignancy-associated HLH (mal-HLH). We initiated corticosteroids promptly (dexamethasone $10 \mathrm{mg} / \mathrm{m}^{2}$ ) on day 54 after chemotherapy initiation but observed progressive pancytopenia and hemodynamic instability over the subsequent days. According to current recommendations [5] for mal-HLH, we continued to treat the underlying malignancy with the third course of R-CHOEP. Despite these measures, the patient deteriorated and died shortly afterwards in a distributive shock.

Further work-up of the histopathological examination of the second bone marrow sample revealed $t(14 ; 18)$ positive HS infiltration and prominent hemophagocytosis within malignant histiocytes (FISH, IHC). The clinical presentation that mimicked secondary HLH was based on refractory HS with bone marrow infiltration and neoplastic hemophagocytosis in the proper sense.

Clinically relevant cytopenia due to hemophagocytosis in HS has been rarely described [6-8]. The combination of hemophagocytosis with pancytopenia and inflammatory response syndrome has not been linked to fulminant HS bone marrow infiltration. This finding is relevant for clinical 


\section{a}

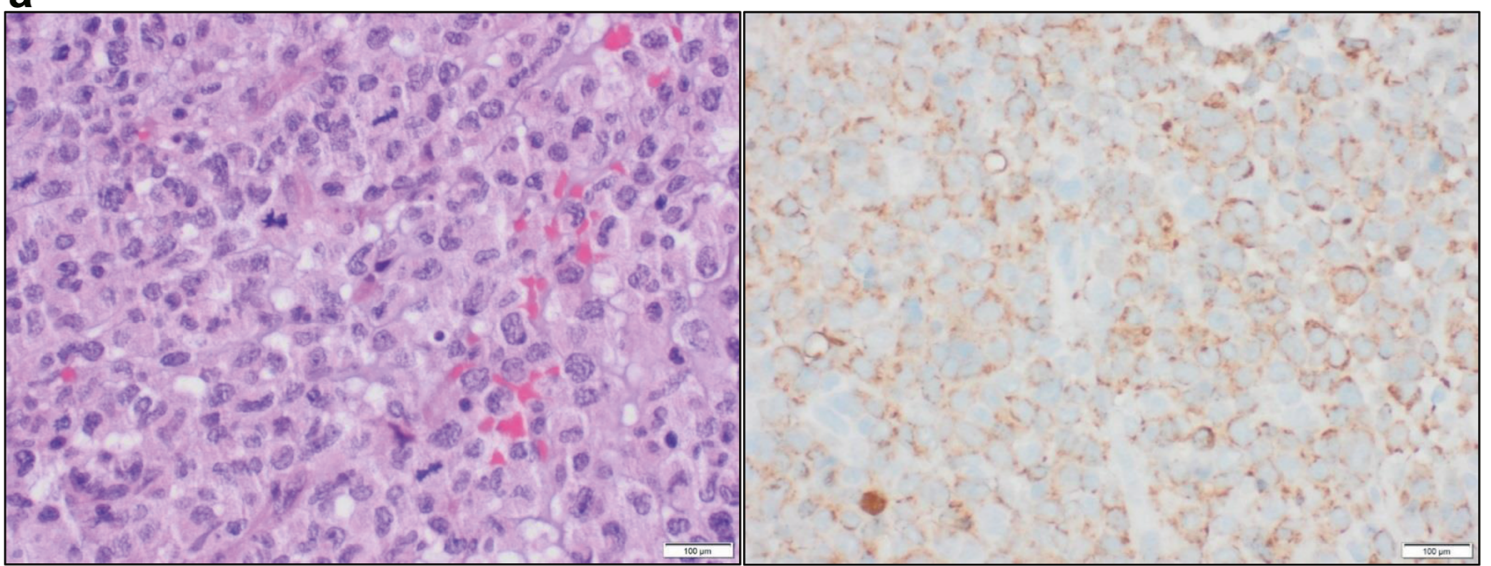

b

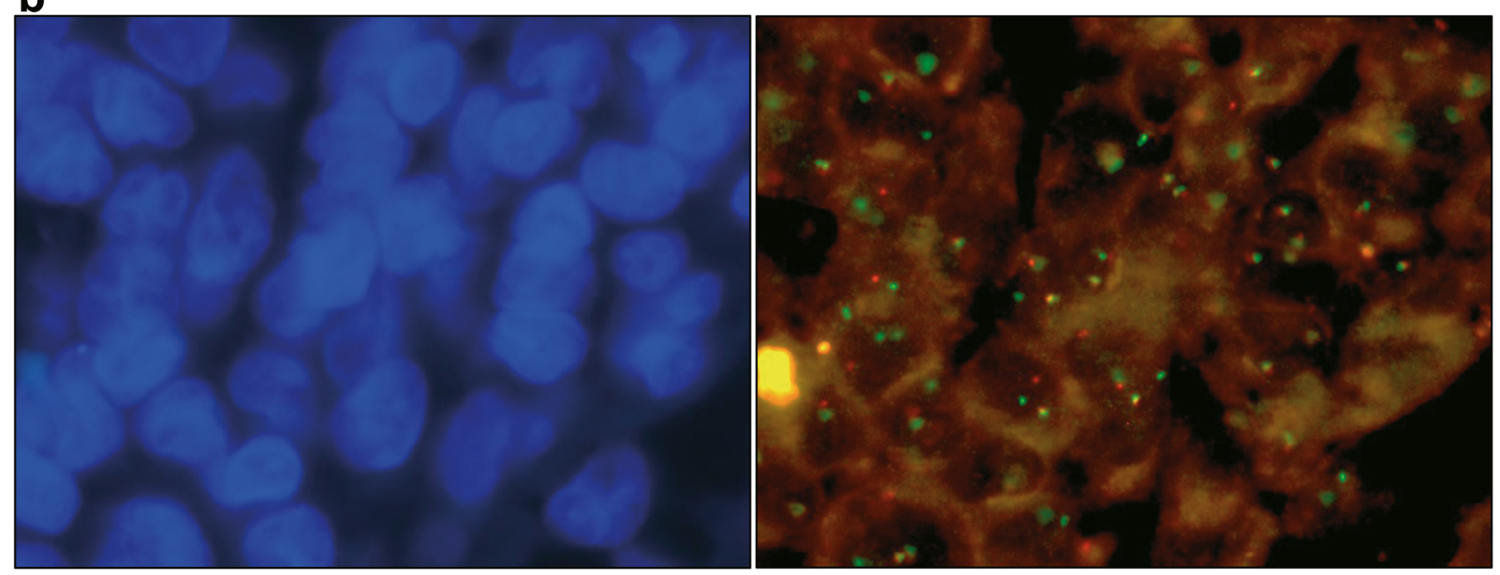

C
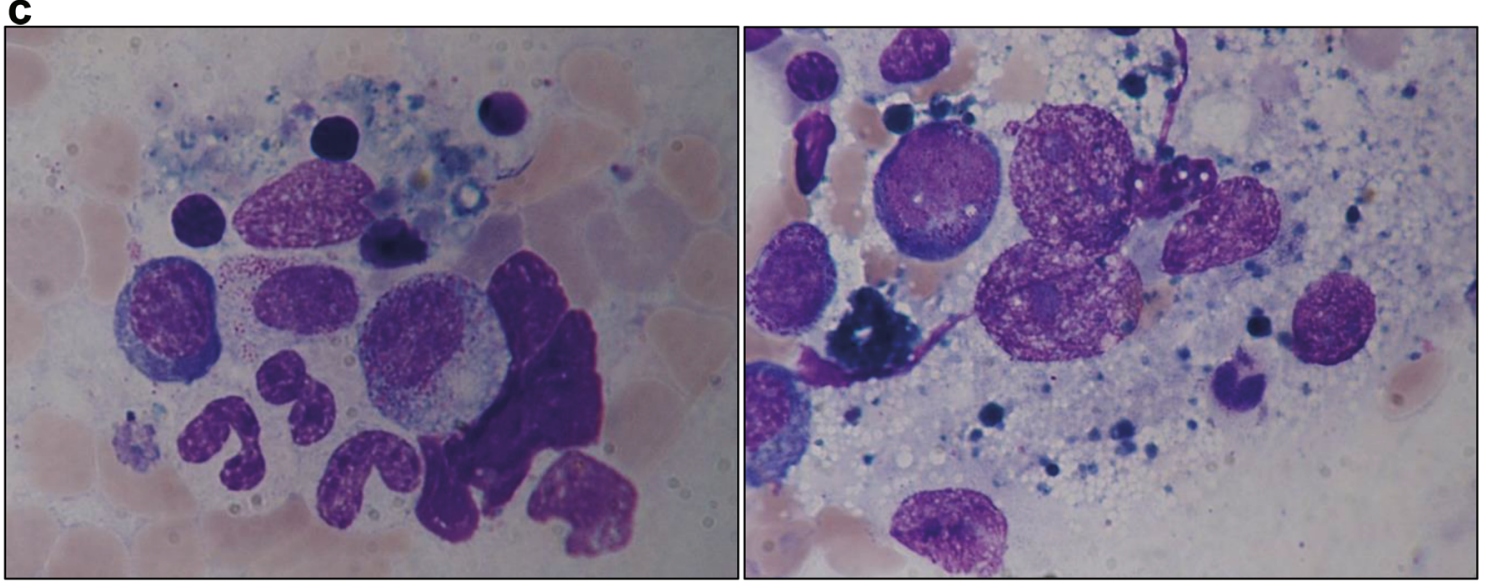

Fig. 1 Histopathological and cytological studies during course of disease. a Histopathology images of a biopsy of a cervical mass with blastic infiltrate and histiocytic sarcoma (HS) immunophenotype. Left: Hematoxylin and eosin (H\&E). Right: CD68 immunohistochemical staining (original magnification $\times 400$, bars represent $100 \mu \mathrm{m}$ ). b FISH analysis of histiocytic sarcoma identified translocation $t(14 ; 18)$. Left: Nuclear staining with DAPI. Right: BCL2 FISH break apart probe

(ZytoLight SPEC BCL2, Zytovision, Bremerhaven, Germany). Orange/ green fusion signal indicated non-rearranged BCL2 gene. Orange and green separate signals confirmed rearranged BCL2 gene (original magnification $\times 1000$ ). $\mathbf{c}$ Day 54 bone marrow aspirate showed prominent wide and polygonal histiocytes with large nuclei and 1-3 prominent nucleoli. The cytoplasm was slightly basophilic and foamy with prominent hemophagocytosis. Pappenheim stain (original magnification $\times 1000$ ) 
management of HS. HS may be considered differential diagnosis for inflammatory syndromes with hemophagocytosis such as HLH, especially when refractory to standard therapy.

Authors' contributions Christoph Schünemann, Arnold Ganser, and Felicitas Thol took care of the patient; Gudrun Göhring, Yvonne Lisa Behrens, and Hans-Heinrich Kreipe analyzed the results; Christoph Schünemann and Felicitas Thol formulated, designed, and wrote the paper. All authors read and approved the final manuscript.

Funding Information Open Access funding provided by Projekt DEAL.

Data availability Not applicable.

\section{Compliance with ethical standards}

Conflict of interest The authors declare that they have no conflict of interest.

Ethics approval This case study was performed in line with the principles of the Declaration of Helsinki. This article does not contain any studies with human participants performed by any of the authors.

Consent to participate Not applicable.

Consent for publication Not applicable.

Code availability Not applicable.

Open Access This article is licensed under a Creative Commons Attribution 4.0 International License, which permits use, sharing, adaptation, distribution and reproduction in any medium or format, as long as you give appropriate credit to the original author(s) and the source, provide a link to the Creative Commons licence, and indicate if changes were made. The images or other third party material in this article are included in the article's Creative Commons licence, unless indicated otherwise in a credit line to the material. If material is not included in the article's Creative Commons licence and your intended use is not permitted by statutory regulation or exceeds the permitted use, you will need to obtain permission directly from the copyright holder. To view a copy of this licence, visit http://creativecommons.org/licenses/by/4.0/.

\section{References}

1. Kommalapati A, Tella SH, Durkin M, Go RS, Goyal G (2018) Histiocytic sarcoma: a population-based analysis of incidence, demographic disparities, and long-term outcomes. Blood 131(2):265268. https://doi.org/10.1182/blood-2017-10-812495

2. Feldman AL, Arber DA, Pittaluga S, Martinez A, Burke JS, Raffeld M, Camos M, Warnke R, Jaffe ES (2008) Clonally related follicular lymphomas and histiocytic/dendritic cell sarcomas: evidence for transdifferentiation of the follicular lymphoma clone. Blood 111(12):5433-5439. https://doi.org/10.1182/blood-2007-11-124792

3. Janka GE, Lehmberg K (2013) Hemophagocytic lymphohistiocytosis: pathogenesis and treatment. Hematology Am Soc Hematol Educ Program 2013:605-611. https://doi.org/10.1182/ asheducation-2013.1.605

4. Henter J-I, Horne A, Aricó M, Egeler RM, Filipovich AH, Imashuku S, Ladisch S, McClain K, Webb D, Winiarski J, Janka G, for the Histiocyte Society (2007) HLH-2004: diagnostic and therapeutic guidelines for hemophagocytic lymphohistiocytosis. Pediatr Blood Cancer 48(2):124-131. https://doi.org/10.1002/pbc.21039

5. La Rosée P, Horne A, Hines M et al (2019) Recommendations for the management of hemophagocytic lymphohistiocytosis in adults. Blood 133(23):2465-2477. https://doi.org/10.1182/blood. 2018894618

6. Mitani S, Kaneko H, Imada K (2018) Bone marrow infiltration of histiocytic sarcoma. Blood Res 53(3):185. https://doi.org/10.5045/ br.2018.53.3.185

7. Tzankov A, Kremer M, Leguit R, Orazi A, van der Walt J, Gianelli U, Hebeda KM (2018) Histiocytic cell neoplasms involving the bone marrow: summary of the workshop cases submitted to the 18th Meeting of the European Association for Haematopathology (EAHP) organized by the European Bone Marrow Working Group, Basel 2016. Ann Hematol 97(11):2117-2128. https://doi.org/10. 1007/s00277-018-3436-0

8. Vos JA, Abbondanzo SL, Barekman CL, Andriko JAW, Miettinen M, Aguilera NS (2005) Histiocytic sarcoma: a study of five cases including the histiocyte marker CD163. Mod Pathol 18(5):693-704. https://doi.org/10.1038/modpathol.3800346

Publisher's note Springer Nature remains neutral with regard to jurisdictional claims in published maps and institutional affiliations. 